$\because:$

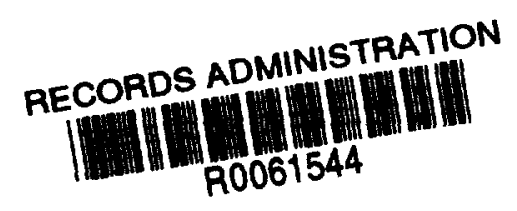

$\int^{66^{6^{3}}}$

DPSPU $62-30-5$

$v_{-1} 180$

\title{
CONTROL OF TRITIUM HEALTH hazARDS AT THE SAVANNAH RIVER PLANT
}

W. C. Roinig

Sovannah River Plant

$$
\text { and }
$$

E. L. Albenesius

Savannah Rlver Laboratory

E. I. du Pont do Nemours \& Co.

Aiken, S. C.

To be presented at the 23rd Annual Meeting of the American Industrial Hygiene Association, Washington, D. C., May 14-17, 1962.

Publisher is requested to include this acknowledgement.

The Information contalned in this article was developed during the course of work under contract AT(07-2)-1 with the U. S. Atomlc Energy Commission. 


\author{
W. C. Reinig \\ Savannah RIver Plant \\ and \\ E. L. Albenesius \\ Savannah River Laboratory \\ E. I. du Pont de Nemours \& Co. \\ Alken, South Carolina
}

\begin{abstract}
INTRODUCTION
The Savannah River Plant is the center of tritium production activity in the United States. Quantities of tritium, sufficient to present a health hazard to operating personnel, are produced by the irradiation of lithium for the scheduled production program and as an unwanted by-product from neutron irradiation of the heavy-water moderator in the reactors(1). Radiological protection is complicated by the low average energy of the tritium beta particles ( $5.7 \mathrm{kev}$ ) and the ease with which the oxide is assimilated through the skin. Although the external radiation hazard from tritium is negligible, all of the oxide that enters the body is absorbed(2). This report is a review of the program at the Savannah River Plant for the control of the radiological hazard of tritium to the employees and to the population in the environs of the Plant.

\section{$\underline{\text { SUMMARY }}$}

The essentlal components of the program for the control of tritium hazards at Savannah River include radiological engineering, training of operating personnel in technlques of protection, protective clothing, control of surface and alr contamination, bloassay and environmental monitoring.
\end{abstract}

Rapid change of air in process areas and the continuous measurement of tritium in air are two important facets of the protection program. Workers in a tritium atmosphere wear inexpensive, polyvinyl suits which are supplied with air and envelop the entire body. Permissible working time limits are established with the help of a nomograph that reflects the tritium concentration in air and the protective value of alr masks or plastic suits.

*The information contained in this article was developed during the course of work under contract AT(07-2)-1 with the U. S. Atomic Energy Commission. 
Employees submit urine specimens after fobs involving tritium exposure. These specimens are immediately assayed by means of liquid scintillation counting. Grease, oll, and other hydrocarbons retain tritium. Surface contamination is detected qual1tatively by use of smears and gas flow proportional counters.

Ventilation air from process areas is released to the environs through tall stacks. The stack alr is continuously monitored. At the perimeter of the Plant and 25 miles away, air is sampled to determine the effect of tritium released through the stacks. The Savannah River, streams on the Plant, and food produced in the vicinity of the reservation are routinely analyzed. The tritium levels in the environs of the Savannah River Plant are substantially less than the limits recommended by the International Commission of Radiological Protection for large populations.

\section{DISCUSSION}

\section{Radiological Engineering}

During the design of the Savannah River production facilities, principles of radiological engineering were applied to insure effective control of the hazard from tritium through isolation and ventilation.

Individual pieces of process equipment are isolated in separate walk-in hoods. The disadvantages of reduced visual contact caused by compartmentalization are overcome by liberal use of transparent "Lucite" windows and walls. The hoods are designed so that equipment may be removed without personnel entering the hoods. Removable panels are used for replacement of equipment and maintenance operat1ons. Air locks are provided for normal entry and exit to limit the spread of contamination from process rooms.

Ventilation systems are designed to direct the flow of all building alr from the offices and operating areas to the process rooms and, then, through the hoods to exhaust stacks. A minimum air flow of $200 \mathrm{fpm}$ is maintained through the opening when a hood is opened; the ventilation method minimizes eddy currents and reverse diffusion. Air pressure in the process rooms is kept positive relative to that in the hoods. The process rooms and hoods are maintained at a negative pressure with respect to the operating areas and offlces. The malntenance of correct pressure differentials is routinely checked by draft gages. Bullding air is released to the environs from the exhaust stacks which are 200 feet high. 
2. Exposure Control and Training

To insure day by day control of the tritium hazard, the Health Physics group must approve each operating and malntenance job that involves potential exposure, and conducts a continuing program of training in radiological safety. Production, maintenance, and health physics personnel plan each job and agree upon recommendations for radiological controls, 1.e., time limits, protective clothing and equipment, and speclal precautions. Before production and maintenance personnel are assigned to tritium work they complete comprehensive training. Early indoctrination in correct work habits contributes to safe operations later. The following toplcs are included in these on-the-job training programs:

1. Chemical, physical, and radiological properties of tritium

2. Operating limits (body burden, alr, and surface contamination)

3. Tritium monitoring techniques and instruments

4. Job planning and preparation

5. Exposure control, including protective clothing and time IIm1ts

6. Control of surface contamination

7. Job techniques (protective measures during line breaks, tool handling, decontamination)

\section{Bloassay procedures}

Retraining in these topics is done on a routine basis.

As a result of the training programs and the experience gained on the job, the production and maintenance worker is well-versed in tritium hazards and controls. He is trained to protect himself in the case of abnormal or emergency conditions. His training gives him pride in his job knowledge, high morale, and confidence that his work can be completed efflciently and safely.

Working time limits and protective clothing are used to limit the exposure of personnel to atmospheres contaminated with tritium so that the body burden of the Individual employee never exceeds 1 millicurie of tritium at any time. A nomograph (Figure 1), calculated on the basis of the standard man, is used to set time limits quickly. Since skin and lung absorption are approximately equal, 
the nomograph also reflects the protective value of resplratory equipment and plastic suits. Plastic sults are worn whenever there is uncertainty concerning the magnitude of the tritium concentrations in air. Since the oxide is more readily assimilated than molecular tritium, all tritium is assumed to be in the oxide form to provide the most conservative radiological approach.

\section{Protective Clothing and Equipment}

In safeguarding personnel working in atmospheres contaminated with tritlum, absorption through skin and lungs must be considered as modes of entry into the body. Tritium oxide penetrates plastic, cloth, and rubber materials ordinarily used in the fabrication of protective equipment. At the Savannah River Plant, two-plece ( 6 mils thick) polyvinyl chloride sults (Figure 2) are worn when maximum protection is required (3). The suit envelops the entire body and alr is continuously supplied at 7 to $15 \mathrm{cfm}$.

Since data relating to the permeation of tritium oxide through plastic films were essentially nonexistent various evaluations of plastic films and sult designs were made (4). The polyvinyl suit was chosen on the basis of 1ts effectiveness as a tritium oxide barrier, low cost, laundering qualities, and comfort. Tests in exposure chambers, under operating conditions, indicated that tritium concentrations in air inside the suit (under equilibrium conditions) were 150 times less than the alr concentrations outside the suit (Figure 3). Tests also showed a time lag between the initial exposure and tritium penetration through the plastic, which offers an additional safety factor when the suits are exposed to sudden increases in activity.

A1r supplies, sultable in quality for breathing purpose, are provided in all locations where tritium is a potential hazard. Portable equipment is avaliable to cool and dehumldify the air where necessary. Long a1r hoses, with couplings that can be disconnected quickly, make 1t practical to don and remove the sults in clean atmospheres. Laundering the sults for re-use by means of household washing and drying machines has been successful but the low initial cost of the suits reduces the savings to a marginal level.

On Jobs where there is a probability of personnel handling highly contaminated equipment, extra protection to the hands is required. Th1s is accomplished by an additional pair of surgeon's gloves worn under the suit's gloves and another palr worn outside the suit's gloves. The outer pair are frequently changed as the job progresses. 
4. A1r Monitoring

Cognizance of the concentrations of tritium in air is an essential ingredient in the protection program. Four instruments are used for alr monitoring; each has a particular application.

Where continuous monitoring is required, Kanne chambers are used (5). These are large ionization chambers through which air is drawn. A typical system includes an intake or sampling line, filter, flowmeter, Kanne chamber (Flgure 4), alr pump, and exhaust line. The current produced by Ionization within the chamber is measured by a micro-microammeter. Two chamber sizes are used at the Savannah River Plant, an aluminum chamber with an actlve volume of 51.5 liters and a stalnless steel chamber with an active volume of 18.5 liters. Alr flow through elther chamber is approximately $3 \mathrm{cfm}$. The amplifiers are logarithmic and the range of the monitoring system for tritium in air is $1 \times 10^{-5} \mu \mathrm{c} / \mathrm{cc}$ to $5 \mu \mathrm{c} / \mathrm{cc}$. Except in the case of inordinately high tritium concentrations, there is no problem with residual internal contamination. If this does occur, decontamination can usually be accomplished by purging the chamber for several hours with heated, deslccated alr, or the chamber can be disassembled for decontamination. Unwanted 1ons, such as those present in exhaust fumes from diesel engines, may cause erroneously high readings if present in large concentrations, even though the chamber contains an ion trap.

Depending upon the hazard potentlal, in some facilities the air in Individual hoods and rooms is continuously monitored by Kanne systems. Where the hazard potential is relatively small, one Kanne system may intermittently monitor several locations or the composite air exhaust from several areas in the bullding. In every case where a stack may release tritium to the environs, it is continuously monitored.

Since the stack monitor provides a continuous record of tritium concentrations, simple integration, elther visual or manual, of the data on the recorder chart indicates the total stack release.

The portable tritium monitor used at SRP (6) is based on the same design as the Los Alamos "sniffer" but, in addition, it has a gammacompensation chamber (Figure 5). The instrument must be exposed to a uniform gamma radiation field for accurate results. It is effective for the measurement of tritium concentrations in air in the range of $4 \times 10^{-5} \mu \mathrm{c} / \mathrm{cc}$ to $2.5 \times 10^{-2} \mu \mathrm{c} / \mathrm{cc}$. Over-all dimensions of the portable monitor are $5 \times 10 \times 16$ inches and the weight is 16 pounds. 
When nonuniform gamma flelds are encountered, ionization chambers (1 liter) and a vibrating reed electrometer for current measurement are used to determine tritium in a1r. The chambers are evacuated and air is admltted at the locations to be monitored. Later, the chambers are coupled to an electrometer. The range of this instrument for the measurement of tritium concentrations in air $1 \mathrm{~s} 1.4 \times 10^{-6}$ to $1.4 \times 10^{-2} \mu \mathrm{c} / \mathrm{cc}$.

In the environmental monitoring program, moisture is concentrated from the atmosphere for determination of its tritium oxide content. A1r is continuously pulled through a silica gel column at a rate of $100 \mathrm{cc} / \mathrm{minute}$ by means of an inexpensive aquarium aerator pump. The columns are replaced weekly. The tritium concentration in the water that is distilled from the desiccant is determined by liquid scintillation counting. The concentration of tritium oxide in the air can be calculated simply from the concentration in atmospheric molsture and the absolute humldity. The minimum sensitivity of th1s procedure 1s $4 \times 10^{-11} \mu \mathrm{c} / \mathrm{cc}$.

\section{Control of Surface Contamination}

Two mechanisms are involved in the contamination of surfaces by tritium or tritium oxide: first, 1sotopic exchange reactions and second, physical permeation of tritium or 1 ts compounds into a surface (7). The first process takes place on surfaces composed of or contaminated with hydrogenous materials such as o1l, grease, wax, etc. When such surfaces are exposed to tritlum gas or oxide, exchange will occur and the surface becomes contaminated. Thus the use of hydrogenous materials is avolded, if practical, in locations where exposure to large concentrations of tritium is probable.

In the second process, physical penetration into a permeable material by tritiated gas or vapor occurs. Th1s process is one of dynamic equilibrium; the gas or vapor is dissolved at one side of the terial at a rate proportional to its solubility and partial pressure. It diffuses into and through the material, and eventually evaporates from the other side.

Decontamination of tritium-contaminated surfaces is difficult. Water, detergents, trichloroethylene, and sodium perborate bleach are moderately effective for decontaminating tools. V1gorous scrubbing of the surface with detergents is a frequently used procedure. Metal surfaces may be decontaminated by heating to $300^{\circ} \mathrm{C}$ for 30 minutes 
followed by a water quench. Detergents added to the water appear to enhance decontamination.

Since decontamination is difficult, every effort is made to avoid needless introduction of equipment and tools into process areas. Tools and other specialized equipment routinely used in process areas are stored there for re-use. Tools with polished metal surfaces are easiest to clean and their use is encouraged. Since rubber and plastics show an affinity for tritium, tools constructed of these materials are avolded wherever possible.

In order to determine the magnitude of surface contamination or the effectiveness of decontamination procedures, a survey technique is necessary. Instruments for detecting tritium contamination on a surface are limited by the very low energy of the tritium beta. Since the soft beta radiation $w 111$ be completely absorbed by less than $1 \mathrm{~cm}$ of alr, the thinnest window material will absorb all tritium betas. The most practical method of monitoring equipment for low and moderate levels of tritium is by means of smears. The standard smear is a 3-cm disc of filter paper. Delayed counting of the smears in the range 3000 to $300,000 \mathrm{c} / \mathrm{m}$ does not result in a significant error if the count is made within 100 hours after they were obtained. The smear technique can be made more sensitive and reliable if the paper disc is wet with an organic liquid such as ofl or glycerol of low volatility. But since the measurement of surface contamination by the smear procedure is semiquantitative at best, this sophistication is seldom used.

Smears are counted in a windowless, proportional flow counter (8). Methane of high purity was orlginally used as the counting gas. Due to 1ts flammab1l1ty and high cost, methane was satisfactorily replaced by a gas mixture consisting of 98 per cent helium and 2 per cent isobutane. The amblent temperature of gas cylinder storage locations must be above $45^{\circ} \mathrm{F}$ or the cylinder pressure must be below $750 \mathrm{ps} 1$ to prevent condensation of the isobutane fraction. Chamber contamination is frequent when the tritium level on the smears $1 \mathrm{~s}$ above $10,000 \mathrm{c} / \mathrm{m}$. Decontamination can be expedited by protecting the chamber walls with a water soluble, strippable coating which is easily removed and replaced. This film is coated with a graphite colloid to provide a conducting surface. To reduce chamber contamination, smears suspected of having tritium levels of greater than $10,000 \mathrm{c} / \mathrm{m}$ are counted with an open-ended GM tube (9) flushed with counting gas. Counting efficiency of this system Is only 2 per cent compared to 50 per cent for the windowless, proportional flow counter. 
Surface contamination in the process areas is kept as low as practical by routine cleaning. In order for equipment to be released from the process bulldings for unlimited usage, the contamination levels on all surfaces must be less than $50 \mathrm{c} / \mathrm{m}$ per 100 square centimeters.

\section{Personnel Monitoring}

Employees submit urine samples at the end of the work day if they were exposed to tritium. Since there is a time lapse between the exposure and equilibrium in the urine, employees normally give samples at least 45 minutes after the last exposure. A minimum sample of one milililter is required to obtain a minimum sensitivity of $1 \mu \mathrm{c} / 1$ by liquid scintillation counting (10). The samples are Immediately analyzed so that a tritium exposure, if any, is determined prior to the employee's return to work. The infinite dose (D) resulting from the uptake is estimated by the following equation:

$$
\begin{gathered}
\mathrm{D}\left(\text { mrem) }=0.73 \cdot \mathrm{T}_{\frac{1}{2}} \mathrm{~B}\right. \\
\text { where } \mathrm{T}_{\frac{1}{2}}=\text { effective half life (days) } \\
\mathrm{B}^{2}=\text { tritium in urine }(\mu \mathrm{c} / 1)
\end{gathered}
$$

For a first approximation, a 12 day effective half Iife of tritium 1s assumed. This 1s later refined by substituting the effective half Iife of tritium for the individual employee. An average effective or biological half life (since for tritium they are equal) of 10 days was recorded in 75 exposure cases during 1960 . In each of these cases, the tritium concentration in urine was greater than $20 \mu \mathrm{c} / \mathrm{l}$. Since tritium retention is a function of body water turnover, the rate of loss is lower in the colder months when liquid consumption is less.

Only in one case have diuretics been administered by the Medical Department to increase the elimination of tritium. This occurred in 1956 when a worker assimilated $153 \mathrm{millicurles.} \mathrm{The} \mathrm{normal}$ effective half ilfe of tritium for this individual was reduced from 14 days to 8.5 days.

The dose resulting from each uptake greater than $5 \mu \mathrm{c} / 1$ is included In the employee's radiation record and added to the penetrating whole body radiation as measured by the film badge. As an administrative control, personnel with body water concentrations of tritium greater than $20 \mu \mathrm{c} / 1$ are excluded from further tritium work unt1l a level of $10 \mu \mathrm{c} / \mathrm{I}$ is reached. 
F1Im badge dosimeters that are exposed to trit1um atmospheres darken due to tritium permeation of the film wrapper. The degree of response of a particular film emulsion depends on a number of variables includIng concentration of tritium, duration of exposure, thickness and permeability characteristics of film wrapping, and badge design. Under normal working conditions, 1.e., when exposure of an employee to tritium results in an assimilation of no more than 1 mililcurie, the film will show no significant darkening. Tests with the Savannah River film badge indicated that exposure to a concentration of $3 \times 10^{-2} \mu \mathrm{c} / \mathrm{cc}$ for 1.3 hours produced an apparent gamma exposure of $3.0 \mathrm{r}$ in the film. Expert appraisal of the exposed film after processing can detect abnormalities that may discount the possibility of a valid beta or gamma exposure. There is a tendency for nonuniform darkening in the film, the beta window may not be visible, or the darkening of the shielded section of the film may be greater than that in the beta window area because of retention of the tritium between the shield and the packet. While none of these eccentricities is consistent, they all occur often enough to assist in differentiating between a beta-gamma exposure and a tritium exposure.

\section{Exposure Experience}

The effectiveness of the tritium protection program at the Savannah River Plant is measured by the bioassay results. The exposure experience is summarized in Table $I$.

\section{Environmental Monitoring}

The Savannah River Plant maintains a continuous monitoring program to determine the concentrations of radioactive materials inside the 320 square mile plant area and in a 1200 square mile area outside the Plant perimeter (11). The policy of the Savannah River Plant is to restrict as completely as is practical the release of radioactive materials to the environment. The primary purpose of the monitoring program is to provide specific data to assist in minimizing releases and to insure that amounts released are well below the permissible levels specified by the International Commispion on Radiological Protection. Tritium is one of several radionuclides that are specifically measured in environmental samples.

Alr and rainwater samples are collected continuously at fifteen monitoring stations spaced around the Plant in two concentric circles. The geometrical pattern of the stations insure that a significant Plant release of radioactivity would be detected regardless of prevaling wind conditions (12). The inner circle follows within a few miles of the Plant boundary whlle the outer circle includes 
an area extending 25 miles from the center of the Plant (Figure 6). Four additional stations are located on quadrants approximately 100 miles from SRP. Th1s system permits a comprehensive survelliance of the atmospherlc radioactivity and in addition makes it possible to differentiate between fallout from weapons tests and releases from the Plant. The maximum weekly and average concentrations of tritium in air and ralnwater at the plant perimeter during the period July 1958 through December 1960 compared to the radioactivity concentration guide ( $R C G$ ) are shown in Table II. The RCG's are based on the recommendations of the International Commission on Radiological Protection pertalning to large populations (13).

Milk from 3 local dairies and 2 farms is analyzed weekly for tritium content. The average concentration during the period July 1958 through December 1960 was $7 \times 10^{-6} \mu \mathrm{c} / \mathrm{cc}$; the maximum average concentration for a single week was $40 \times 10^{-6} \mu \mathrm{c} / \mathrm{cc}$. The maximum average weekly concentration was 13 per cent of the $11 \mathrm{mit}$ recommended by the ICRP for the drinking water of large populations.

Routine discharge of spent fuel elements in the Reactor bulldings transfers some of the heavy water moderator and 1ts associated tritium to cooling basins. The cooling basin water is purged continuously to maintain water clarity and control temperature. Some radioactivity is released to the environment in these effluents which are inaccessible to the public since they flow through Plant property until they reach the Savannah River. The effluents and the river are sampled continuously at 42 locations by means of proportional samplers. Average tritium concentrations in the river immedlately downstream from the Plant during the perlod $7 / 58$ through $12 / 60$ are shown in Table III. 


\section{REFERENCES}

(1) Patterson, C. M.: Proc. U. N. Intern. Conf. Peaceful Uses Atomic Energy, 2nd, Geneva, 23: 295 (1958).

(2) Pinson, E. A. and W. H. Langham: Physiology and Toxicology of Tritium in Man. Appl. Physiol. 10: 108 (1957).

(3) Butler, H. L. and R. W. Van Wyck: Integrity of Vinyl Plastic Suits in Tritium Atmosphere. Heaith Physics 2: 195.

(4) Symonds, A. E.: Evaluation of Plastic Films for Protective Suiting. E. I. du Pont de Nemours and Co., Aiken, S. C. AEC Research and Development Report DP-528 (1960).

(5) Hoy, J. E.: Operational Experience with Kanne Ionization Chambers. Health Physics 6: 203 (1961).

(6) Anthony, J. D.: Portable Monitor for Tritium in Air. Nucleonics 17: (No. 4) 110 (1959).

(7) Symonds, A. E.: Removal of Tritium Contamination from Surfaces of Metals. E. I. du Pont de Nemours and Co., Aiken, S. C. AEC Research and Development Report DP-367 (1959).

(8) Butler, H. L. and R. W. Van Wyck: A Synopsis of Studies Related to Tritium Monitoring and Personnel Protective Techniques. E. I. du Pont de Nemours and Co., Aiken, S. C. AEC Research and Development Report DP-329 (1959).

(9) Wilson, J. N.: Instrument Development at the Savannah River Laboratory. Nucleonics 17: (No. 12, Part III) 86 (1959).

(10) Butler, F. E.: Determination of Tritium in Water and Urine. Anal. Chem 33: 409 (1961).

(II) Radiological Health Data. U. S. Dept. of Health, Education and Welfare. I: (No. 9) 4I (1960).

(12) Horton, J. H.: Design of a Regional Survey Program. E. I. du Pont de Nemours and Co., Aiken, S. C. AEC Research and Development Report DP-253 (1957).

(13) Report of ICRP Committee II on Permissible Dose for Internal Radiation, 1959. Health Physics 3 (1960). 
TABLE I. TRITIUM EXPOSURE EXPERIENCE

No. Assayed

$$
\begin{array}{llllllll}
\text { Year } \rightarrow \frac{1954}{2190} & \frac{1955}{2310} & \frac{1956}{2230} & \frac{1957}{4000} & \frac{1958}{3600} & \frac{1959}{2590} & \frac{1960}{2720} & \frac{1961}{2690}
\end{array}
$$

Tritium Assimilations

0.37-1.0, mc

$>1.0, \mathrm{mc}$

Max. Assimilation, mc

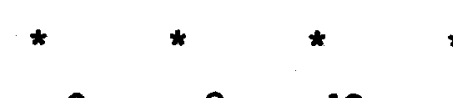

0

$-$

213

$1.2 \quad 153$

* Data not tabulated prior to $\begin{array}{lllll}* & 307 & 156 & 452 & 401\end{array}$

$\begin{array}{lllll}49 & 33 & 22 & 79 & 73\end{array}$

$\begin{array}{lllll}8.8 & 3.6 & 3.2 & 3.9 & 14.6\end{array}$

TABLE II. TRITIUM IN AIR AND RAINWATER *

Air, $\mu c / c c$

$\frac{\text { (multiply by } 10^{-9} \text { ) }}{\frac{\text { Avg }}{0.5} \frac{\text { Max Weekly }}{6.8} \frac{\text { RCG** }}{20}}$ 1958.

* At Plant perimeter 7/58-12/60.

Rainwater, $\mu c / c c$ (multiply by $10^{-6}$ )

\begin{tabular}{|c|c|c|}
\hline & (mulitipi) & \\
\hline Avg & Max Weekly & RCG** \\
\hline 16 & 180 & 300 \\
\hline
\end{tabular}

* Radioactivity Concentration Guide.

\section{TABLE III. TRITIUM IN RIVER WATER}

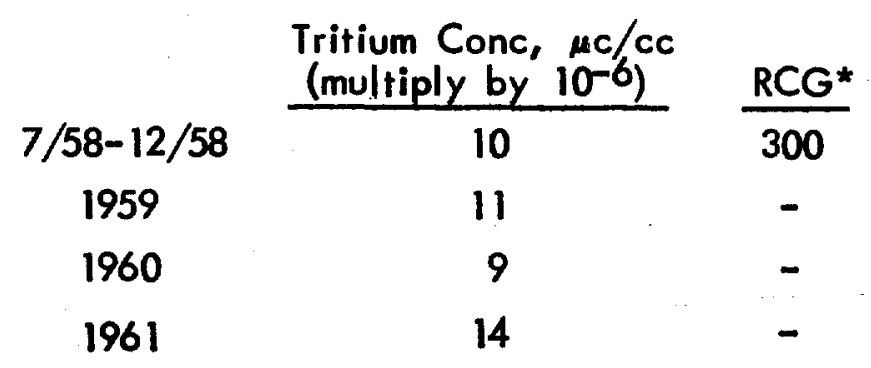

* Radioactivity Concentration Gulde. 
FIGURE I. NOMOGRAPH FOR THE DETERMINATION OF WORKING TIME LIMITS

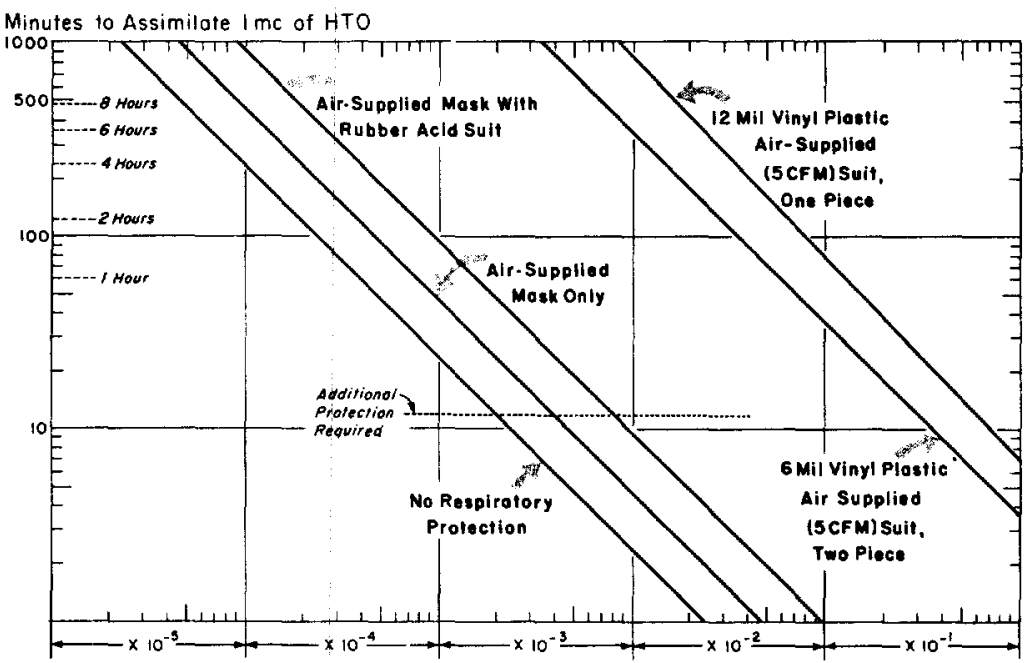

Air Activity, $\mu \mathrm{C} \mathrm{HTO/CC}$

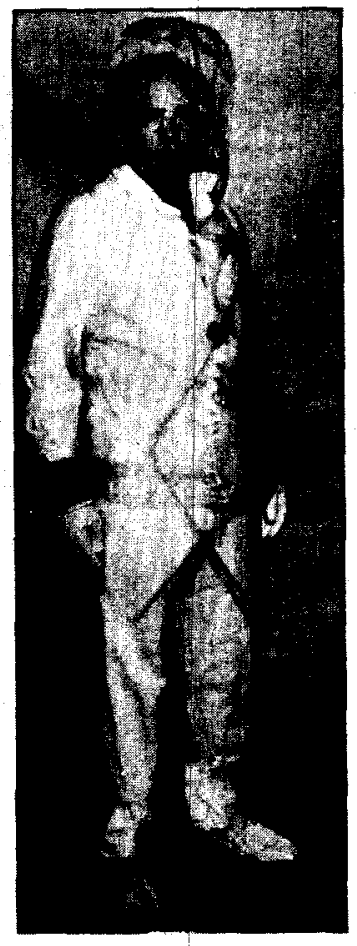

FIGURE 2. TWO-PIECE

PLASTIC SUIT 
FIGURE 3. TRITIUM OXIDE PERMEATION THROUGH AIR-SUPPLIED SUITS

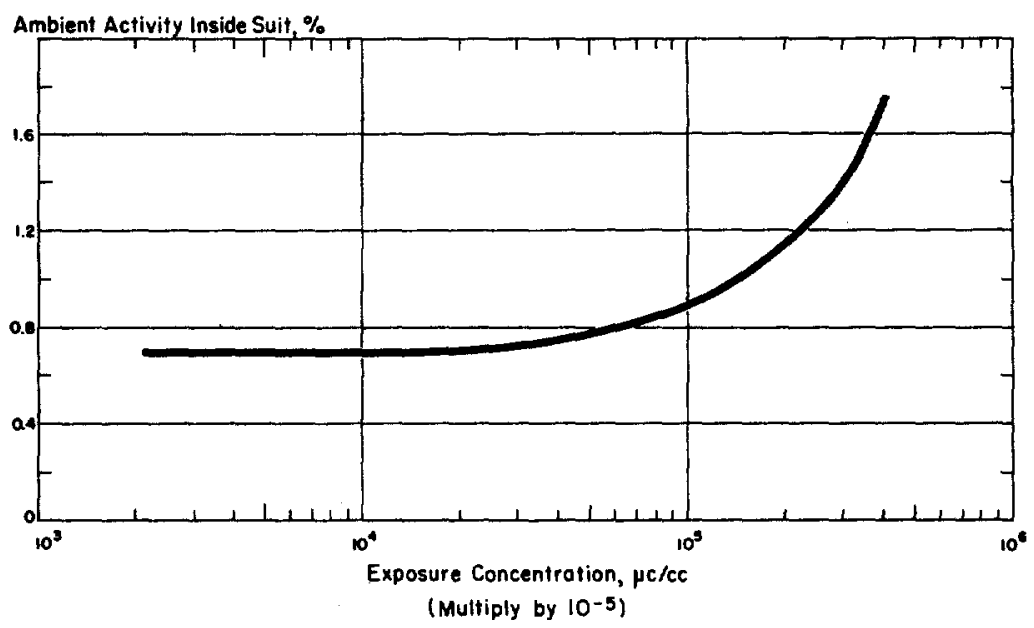

FIGURE 4. KANNE CHAMBER

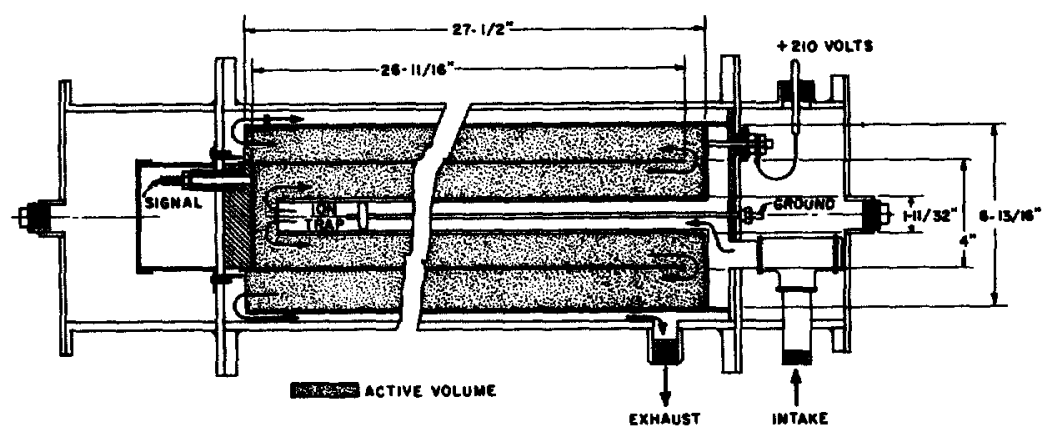
Note: Acfive volume of chomber $\cong 18.5$ fiters 

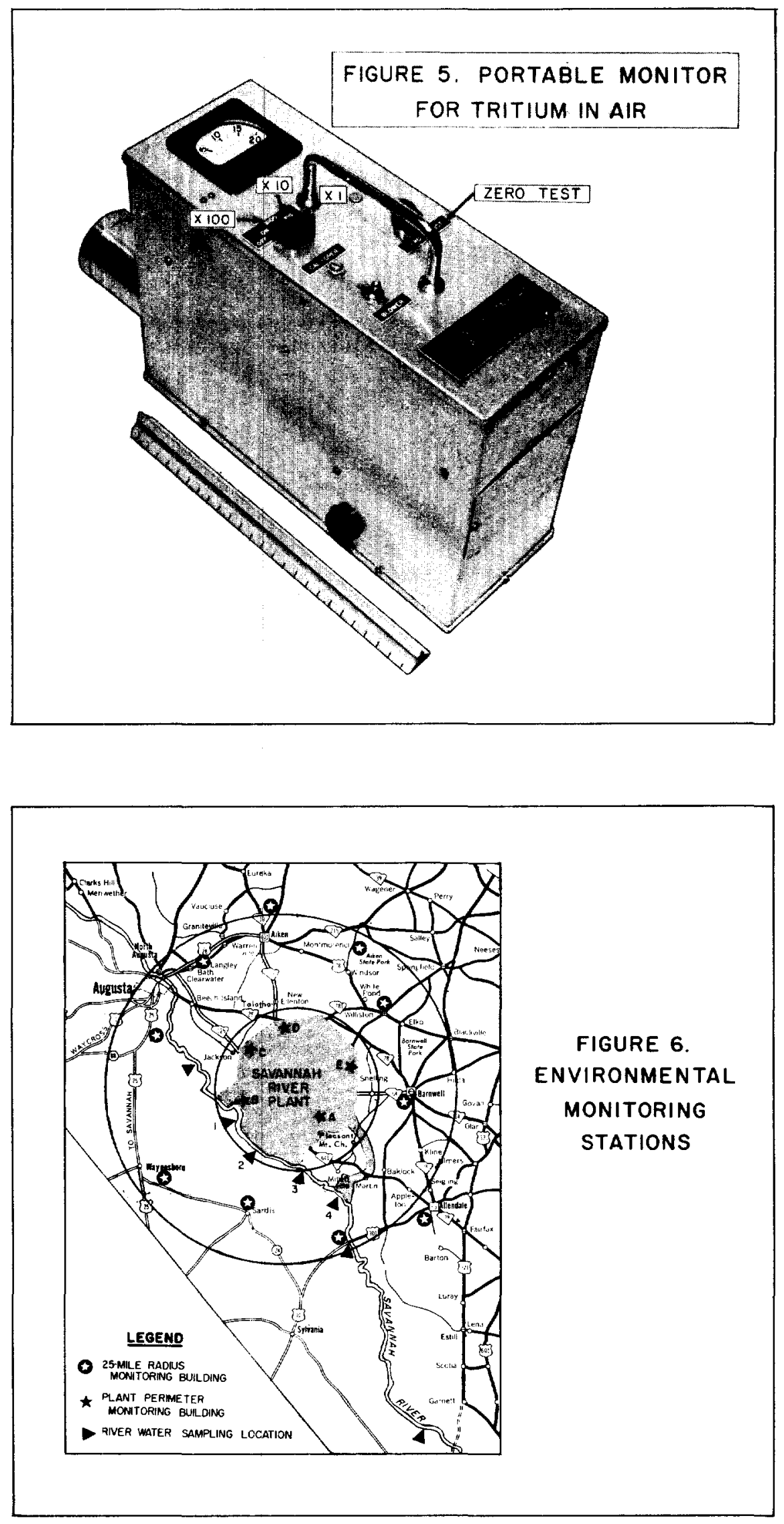